\title{
Validating the Impact of FIRST as a New Learner Experience Framework for Teachers Professional Development
}

\author{
Mohamed M. Bahgat, Ashraf Elsafty and Ashraf Shaarawy*
}

SeGa Research Center, United States

\begin{abstract}
Teachers' Professional Development 'TPD' has always been an area of growing interest in educational research. Several researchers have thoroughly explored the TPD domain aiming to develop and train teachers on how to understand, experience, practice and have a sustainable impact on learners. FIRST (Bahgat et al. 2018) is a new learner experience framework, which consists of five domains; focusing on learner ' $F$ ', interacting within group dynamics ' I', reviewing actively ' $R$ ', structuring and sequencing ' $S$ ', and transforming learning into performance ' $T$ '. It is designed based on educational psychology, neuroscience, and cognitive psychology, to create a framework that promotes active deep learning and inspires a positive transformation in mindset and behaviours. FIRST was applied on a TPD program named Roadmap of Outstanding Educators 'ROOTS'. The participants were one hundred and seven teachers. This paper attempts to explore the impact of FIRST Framework on TPD, teachers experience as learners and teachers motivation to transfer their learning into performance in the classrooms. The study employed exploratory sequential mixed methods design using case study methodology. Qualitative data was analysed and interpreted into codes and themes. Quantitative data was analysed using SPSS. Major findings: (1) Teachers reported that FIRST is comprehensive and compiles various educational theories, models and strategies, they were able to apply the principles and strategies in their classrooms immediately after the professional program days were over, (2) Student's feedback and overall experience were enhanced, (3) Some schools has adopted FIRST as a learner experience. These findings recommended that teachers should live the TPD experience as learners. The TPD programs should include follow up phase to enhance teachers' experience and encourage the transfer of learning into performance.
\end{abstract}

Keywords: Active Learning; Deep Learning; Student Experience; Teachers Professional Development

\section{Introduction}

Teachers' Professional Development (TPD) affects the quality of teachers and their teaching methods which may affect the learning of their students. Many researchers have thoroughly explored the Teachers' professional development domain with the efforts to develop and train teachers on how to understand, experience, practice and leave a sustainable impact on learners (Kennedy 2005; Koster et al., 2008). FIRST framework has been developed by SeGa Group which is a research-based talent development organization established in US (Bahgat et al. 2018).

FIRST framework includes 5 main domains, and 15 principles. These principles integrate together to create an active deep learner experience. It is a holistic framework that is based on other models and theories, such as: experiential learning by Kolb and John Dewey; cooperative learning by Kagan; Carl Rogers' facilitation skills, Roy's 6Ds and learning transfer; as well as positive psychology principles and it also adopted group coaching to promote deep change. FIRST framework also aims to transform learning into performance. The five domains are: Focusing on learner behaviour "F"; to observe each single learner's behaviour during the session and how the facilitator interacts with every individual learner to help the learner feel the experience is unique and customized. The focus of this domain is on every learner and not the overall learners. This domain's principles are: Individualization, Probing/Assessing and Trust the learner. Interacting within positive group dynamics "I"; 
this domain focuses on the interaction between learners and the group dynamics, which results in a unique experience for each group. This means that the same learner can have a different experience if he/she interacts with a different group of learners. The main principles are; Social Event, Positive Spirit, Motivation \& Attention. Reviewing activities " $\mathrm{R}$ " where the focus is on learning activities and how to review them actively. It focuses on the full experience of the activity, how to increase participants' readiness and how to actively review the activity to deepen the learning. Reviewing domain principles are: Readiness Increase, Activity Facilitation, and Reviewing Actively. Sequencing activities "S" is the main focus of this domain, which is the full experience of the trip itself. So, facilitators combine the individual experience "F", with the participants' interactions "I" and how all participants live the experience of the activity "R", in addition to how to make the whole day engaging for learners. What is the full experience of the trip from the first to the last minute? What is interaction within the whole trip? And how all activities are linked and sequenced together to form the trip's full experience? All these questions lie within the $\mathrm{S}$ domain through 3 main principles; Structuring and Sequencing, Repetition without Boredom, Linking and Summarizing. Transforming learning into performance domain " $T$ " deals with how to transfer this learning into action, this domain focuses on what activities and actions can be done within the training room that would help the learner to keep an eye on the practice and the learning transfer, as well as helping in the follow up and mentoring phase that takes place after the trip. The main principles here are; Reflection on Reality, Practicing and Experiencing, Continuity and Follow-Up.

NAMA Foundation, established in Malaysia in 2004, is an organization that focuses on education and capacity building of educational organizations. NAMA has partnered with SeGa Group to achieve the mission of transforming teachers into facilitators who are able to promote memorable learning experience and sustainable impact for their learners. The program titled 'ROOTS' was an intensive TPD program targeting teachers in 8 different countries. The program utilized blended learning where the face to face training took place in Malaysia and online approach for the coaching and mentoring. The program started with a selection stage, where the participants have been selected based on predefined criteria, such as their level of proficiency in English language and their level of experience in teaching and teaching educators Karalis (2016). The participants represented a variety of professional backgrounds; teacher educators, school principals and faculty members, some of them have master degree and $\mathrm{PhD}$ in education. At the second stage, participants enrolled on what is called "a pre-trip" where they received an orientation on the program objectives through online meetings using Zoom software. After that they were introduced to the FIRST framework concepts through micro-learning videos and articles which elapsed for one week. During this stage, the twenty participants were divided into teams, each team consisted of four or five participants and each team was assigned to a mentor from $\mathrm{SeGa}$ specialists who arranged online meetings with them to get their insights and feedback about the micro-learning through Zoom online meeting software. The third stage consisted of a face-to-face training program "learning trip" which lasted for 6 days where participants were invited to fly to Malaysia to attend the training program which was conducted by one facilitator from $\mathrm{SeGa}$ with the help of three co-facilitators. The fourth stage was mentoring and coaching which continued over three months of follow-up with the participants in order to assure they are practicing and applying their newly acquired knowledge and skills, as emphasized by Kennedy (2005). Each participant was required to conduct three to five facilitation session and record them on video then send those videos to SeGa mentors and assessors to evaluate his performance against the benchmarks of FIRST framework (Bahgat et al. 2018). During this stage each participant received feedback about his/her videos through a one-to-one meeting with SeGa mentor. In the fifth stage of the program, participants enrolled to a Community of Practice $(\mathrm{CoP})$ with their coaches and mentors. $(\mathrm{CoP})$ has the importance of exchanging professional knowledge and experience (Wenger, 1990). The interactions took place over online social media using "WhatsApp" program. Those interactions aimed to exchange participants' insights and experiences while practicing FIRST framework. The aim of this study is to investigate the impact of ROOTs TPD program. The participants were one hundred and seven educators who were divided into five groups; each group has twenty or more educators. Each group experienced the first phase throughout four months. The program structure has been repeated with each group. 


\section{Literature Review}

\section{Professional Development of Teachers}

There is no single definition for teacher professional development in educational research, different researchers defined TPD in variant ways according to their views of teacher's roles and work setting (Kelchtermans, 2004). Some researchers focus their definition of TPD on teacher as an individual, Glatthorn (1995) views TPD as a professional growth that teacher can achieve through acquired experience and self-reflection of his or her teaching practices. However, this view overlooks the role of teacher's relationship with his colleagues, students and different educational settings (Grossman, 1994). Many researchers defined TPD in a broader view related to several aspects of educational research (Guskey and Huberman, 1995). The researchers agree to a great extent with Day's (1994, p. 4) definition of TPD which supported the broader view of TPD and its moral purpose and defined professional development of teacher as:

"The process by which, alone and with others, teachers review, renew and extend their commitment as change agents to the moral purpose of teaching; and by which they acquire and develop critically the knowledge, skills and emotional intelligence essential to good professional thinking, planning and practice with children, young people and colleagues through each phase of their teaching lives".

From this definition TPD can be viewed as a lifelong learning that continues throughout teacher's professional life (Day, 1999; Longworth, 2001), this continuous learning and professional development can take place in formal settings such as training programs (Ganser, 2000; Craft, 2002) or informal settings such as coaching and community of practice (Wenger, 1998). However, many TPD programs still consider TPD as a form of traditional training program where teachers usually participate in a series of sessions and workshops that are conducted either inside the educational institution or most commonly off-site at the trainer's premises (Guskey, 2000; Kennedy, 2005). This model of training programs with no follow up has been questioned and criticized because it lacks the connection with the actual classroom settings and day to day educational practices and it may overlook teachers' training needs and their previous teaching experience (Fullan, 2000; Guskey, 2000). Therefore, many researchers and educational authors have suggested new approaches for TPD models which include formal and informal practices (Fraser et al., 2007) such as coaching, mentoring, study groups and community of practice (Wenger, 1998; Guskey, 2000; Kennedy 2005).

Whereas the traditional training model aims to equip teachers with knowledge and skills, coaching and mentoring aims to support teacher professional development through helping them to practice and sustain the knowledge and skills they gain in the training. In addition, CoP builds on social learning theory identified and studied for the first time by Lave and Wenger (1991) where learning within a community of practice takes place informally as a result of interactions and group dynamics among its participants. CoP may help participants to learn, construct a new knowledge and experience based on the individual experience and knowledge of its members and foster transforming of knowledge and experiences (Kennedy 2005; Akhavan et al. 2015).

\section{Research Questions}

This paper studies the impact of 'ROOTs' program on its participants. To achieve this purpose, the following research questions were formed:

Research Question 1: What is the impact of FIRST framework on teachers experience as learners during ROOTs professional development program?

Research Question 2: What is the perception of teachers about the relevance of FIRST framework as a teacher professional development program? 
Research Question 3: What is the impact of FIRST framework on teachers after finishing the ROOTs professional development program?

Research Question 4: What is the impact of FIRST framework on students experience after applying FIRST framework with them in the classroom?

Research Question 5: What is the impact of FIRST framework on schools and educational organizations after applying FIRST framework?

\section{Methodology}

This study was an exploratory sequential mixed methods design and it aimed to explore teachers experience about the FIRST framework as a TPD (Creswell, 2014). The methodology employed was case study which enables researchers to investigate a program intervention in its real-life context and within its bounded system (Yin, 2014; Creswell (2014). The program participants were 107 participants: sixty four females, sixty one males, who represents 8 countries as follows: 17 from Kyrgyzstan, 31 from Indonesia, 14 from Lebanon, 22 from Tanzania, 13 from Malaysia, 3 from India, 5 from Palestine, 2 from Yemen. The data were collected from all participants of the program on both qualitative and quantitative bases. The qualitative data were collected using focus group, qualitative surveys, teachers' testimonials and observations using two methods; first by observing the teachers during the course and taking notes, second by observing them through a video recorded sessions while practicing in their classrooms. The quantitative data were collected through surveys administered to the participants of the program.

\section{Data Analysis}

The Qualitative data was analysed into codes and themes as recommended by Creswell (2014) using MaxQDA software. Quantitative data were collected using self-administered surveys to program participants and analysed using SPSS software, using Factor Analysis of Kaiser-Meyer-Olkin (KMO) and Bartlett's test of Sphericity, generating separate factors (Field, 2009). Testing with Chi square of and significance value of 0.000 (Hair et al., 2010), and Eigenvalues greater than one (Tabachnick and Fidell, 2007). For Reliability test Cronbach's alpha was used to assess the internal consistency and to test the reliability of factors.

\section{Qualitative Data Analysis}

Figure 1 illustrates the emerged themes and codes from the qualitative data analysis. 


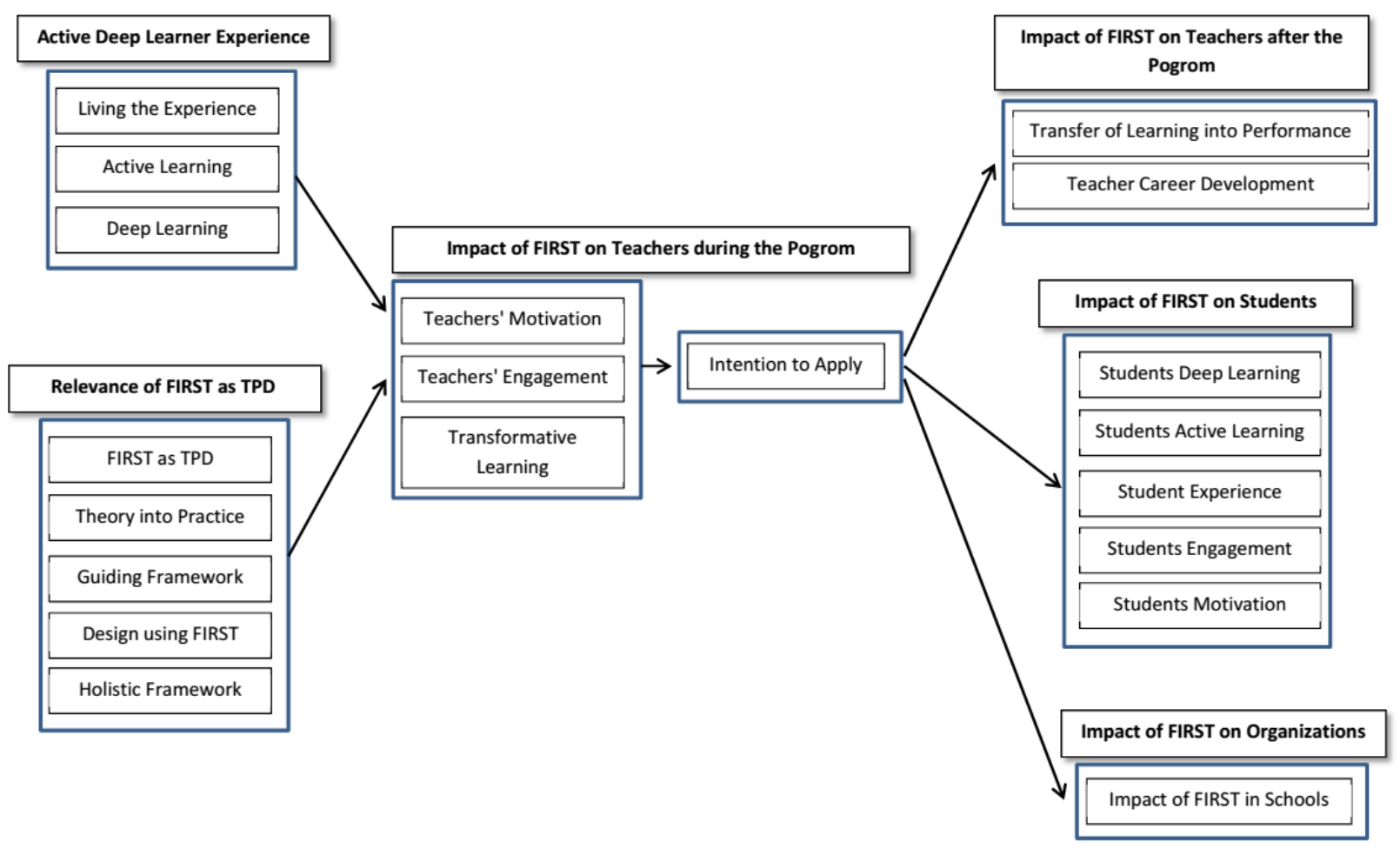

Figure 1 Qualitative analysis using the MaxQDA

\section{Theme 1: Active deep Learner experience}

\section{Teachers live the experience as Learners}

Research studies about TPD suggest that teachers should live the learning experience as learners to be able to provide this experience to their students (Bransford et al. 2000; Bahgat et al. 2018). Learning experience includes every experience they live during the learning journey such as the facilitation method of the educator, curriculum and content, learning activities (Harvey et al. 1992; Benckendorff et al. 2009). Learning experience of learners is complex and has different facets; it is in the mind of the individual who has been engaged in the experience emotionally, cognitively, physically or even spiritually (Pine and Gilmore, 1999; Benckendorff et al. 2009). The participants described their learning experience as:

"Learning about FIRST was an amazing experience with respect to me, I can't really find exact words of appreciation as this experience, which is still going on, it is really what I have been searching for in my teaching life. We lived an enjoyable and memorable experience.” (A Female Participant)

\section{Teachers' Active Learning}

Active Learning is defined as "instructional activities involving students in doing things and thinking about what they are doing" (Bonwell and Eison, 1991, p.5). Employing active learning may result in enhanced learner experience (Georgiou and Sharma, 2014). This may lead to transfer of learning into performance (Subedi, 2004). Participants described their experience about the session as: 
"With FIRST we can make the learner to be active, all the topics are learnt deeply and sustainably. The aim of our learning process (outcome) is the deep learning which depend on understanding and recalling when it's needed not just memorize the information to forget it after the traditional exams." (A Male Participant)

\section{Teachers' Deep Learning}

Biggs and Tang (2011) asserted that deep approach encourages learners to seek underlying meanings, relate new knowledge to prior experience, analyse and evaluate the new knowledge. Laird et al. (2005) suggested that when educators use deep learning strategies, learners tend to retain, integrate and transfer information at higher rates and live more enjoyable learning experience. One of the indicators of deep learning as suggested by Biggs and Tang (2011) is the willingness of the learner to know more information about the topic beyond the curriculum. One participant:

"I am eager to know a lot about it in order to practice it more and more, I will deepen my knowledge on this framework and live with it." (A Female Participant)

\section{Theme 2: Relevance of FIRST framework}

\section{FIRST as a TPD Program}

As suggested by (Angadi, 2013; Rose and Reynolds, 2006) teacher professional development programs should be relevant to teachers' needs. According to Timperley et al. (2007), teachers in TPD program are more likely to be engaged if they find the program relevant to their professional career. Teachers who participated in the program described it as:

"I applied some principles before but not as organized as FIRST. I see that teachers should study

FIRST as a perquisite to be able to start teaching." (A Female Participant)

\section{FIRST as a guiding framework}

From the researchers' interpretation of the qualitative data of program participants, teachers described how FIRST framework provided them with guidance during the teaching or training sessions.

"FIRST framework gives the teacher a guidelines to plan and facilitate their activities with students as stated by the teachers that: before the training I had a vision to make real change, now I know and I have a guide provided by FIRST to follow this training." (A Female Participant)

\section{FIRST transforms theory and Practice}

Some of the participants hold a PhD degree in teaching, while others hold a master's degree in teaching and they all have a good experience with the learning and teaching theories and models, those participants expressed how FIRST advances those theories into practices:

"FIRST has managed to surprise me one more time in its immense ability of linking theory to practice. After getting my master's degree at the University of Balamand, I started implementing Learner Centric classroom in my classes; however, something was a bit missing. FIRST framework proves to be a suitable complement for what was missing. FIRST is about theories into practical actions" (A Male Participant).

\section{Design using FIRST}


The learning design is about creating the conditions and utilizing the available resources to provide facilitators with the activities, content and session flow that help them motivate their learners to learn (Mor et al. 2013). The participants learnt how to do this and how to manage the session flow along with the flow of the whole learning journey or program as described by one participant:

"I used the 15 principles of FIRST while designing my lesson classes and that was the main concept that led me to really express and apply the change among the work. I did feel the difference during my planning in terms of organization and taking into consideration the domains and principles, in addition to the practice itself." (A Male Participant)

\section{FIRST as a Holistic framework}

Bahgat et al. (2018) claimed that FIRST framework is designed to be a holistic framework that synthesis the different theories and models of learning and education. Qualitative data from teachers who attended FIRST program supported this claim:

"I believe that FIRST is a "Complete Scheme" and a "perfectly designed framework", each principal in FIRST is easy to understand, useful, and also practical in learning activities. Put them altogether; raise it to a whole new dimension of experiencing deeper meaningful learning experience." (A Female Participant)

\section{Theme 3: Impact of FIRST during the program}

\section{Teachers' Engagement}

Learner engagement is a complex concept with multi-components (Trowler, 2010). Boud et al. (1993) suggested that "learning can only occur if the experience of the learner is engaged, at least at some level" (p. 8). Educational researchers have identified three levels of learner engagement: behavioural, emotional and cognitive (Pintrich and De Groot 1990; Gregory et al. 2013). Participants described their experience of the engagement during the program:

"It engages the learners in a whole learning experience, it's a great way to grab students' attention and kill boredom." (A Male Participant)

\section{Teachers' Motivation}

Motivation refers to learners' desire and willingness to deploy effort toward and persist in the learning task (Ratey, 2001; Schunk et al. 2008). Many researchers suggested that teachers as adult learners consider motivation as one of the important concepts to a successful TPD (Castañeda, 2016). Moreover, a common problem that faces facilitators is learners' reticence in the training room which can be mitigated by establishing safe environment in the training room (Marchand, 2012). Participants described their experience as:

"The participants of the program including myself were highly motivated to share and to express things during the sessions without being afraid or shy and to complete the required missions after the sessions" (Female Participant)

\section{Transformative Learning using FIRST}

Transformative learning theory is based on the constructivist approach where it emphasizes on the previous experience that adults accumulate throughout their lives which constitutes their frame of reference "learning is understood as the process of using a prior interpretation to construct a new or revised interpretation of the meaning of one's experience in order to guide future action" (Mezirow, 1996, p. 162). For learning experience to be transformative, educators should introduce adult learners to different perspectives that challenge their frames of reference within a safe environment and mutual trust (Taylor, 2000). This could encourage adult 
learners to question their held beliefs, feelings and thoughts which could help them change their attitudes and apply the relevant skills and experiences that they newly acquired (Mezirow, 1994; Curran and Murray, 2008). As stated by a participant:

"This training Experience really changed my perception, it had a very big impact in my perspective about my role in teaching, I now have a new role as a facilitator, my new role shouldn't be teaching, it should be motivating learners to learn. I discovered that the problem is not in the students, the problem is in the teachers, and the teachers should be educators." (A Female Participant)

\section{Intention to Apply}

Individual's behaviour can be predicted by his or her intention towards that behaviour (Ajzen and Fishbein, 1980; Ajzen, 1991). According to Aiello and Sharma (2018), teachers' implementation of what they trained on in TPD programs can be predicted from their intentions to engage and apply the newly gained strategies. Many participants expressed their intention to apply what they learnt in the program into their classrooms:

"After this training I feel very enthusiastic, I should plan meetings with my university teacher to agree with them to apply FIRST." (A Male Participant)

\section{Theme 4: Impact of FIRST on Teachers after the Program}

\section{Transfer Learning into Performance}

Middleton and Baartman (2013, p.2) reviewed that Thorndike and Woodworth (1901) defined transfer of learning as "a product of the learning process where something learned in one context is used to assist learning in another context". Transfer of learning can be viewed as application of learning acquired in the training into workplace (Gagne et al.1993). Most of the participants reported that they implemented the strategies and skills that they gained during the TPD program in their classrooms:

"I began implement F.I.R.S.T framework with 15 principles to my students immediately after I came to Kyrgyzstan." (A Male Participant)

\section{Impact of FIRST on teachers' career development}

TPD programs aims to achieve the institutions objectives regarding the impact on students and the teachers' objectives which include, among different objectives, their career development (Bharati and Chalise, 2017). Many participants of the ROOTs program expressed how the program contributed to their carrier development:

"This learning experience motivated me to become a better and effective teacher. As a teacher, who has been teaching for 12 years, sometimes I feel boredom, running out of ideas about how to make learning enjoyable without forgetting the ultimate aim of the learning process, for me teaching was like a routine but after I joined the Roots Program and learned a lot about FIRST Framework, I became more excited in teaching. It tackles the development of teachers and promotes their roles into facilitators and coaches." (A Male Participant)

\section{Theme 5: Impact of FIRST on Students after the Program}

\section{Students' Deep Learning}

Biggs and Tang (2011) suggested that deep learning can be manifested through the willingness of the students to know more about the topic beyond the curriculum and to be able not to just memorize it but to apply it in real life situations as expressed by teachers about their students:

"The aim of our learning process (outcome) is the deep learning depends on understanding and 
recalling when it's needed not just memorize the information to forget it after the traditional exams. I have witnessed how my learners were able to reflect on their reality and by facing the real problems that emerge when they go deeper during their inquiry then suggesting solutions for each problem. Also they were motivated to proceed on their learning even beyond the learning trip." (A Female Participant)

\section{Student Active Learning}

Bonwell and Eison (1991) proposed that for the learners to be active, they should not only listed to their educator but also they should write, read, discuss and solve problems.

"Students began to express and share their reflections, thoughts and opinions more than ever, more pair and teamwork, more interaction between the students, more questions about real applications in life, and even some shy or passive students began to feel safe and step by step began to participate. They loved the fun activities that have mirrored real-life situations." (A Male Participant)

\section{Student Experience}

Manthiou et al. (2011) suggested that a good learning experience can affect emotion and last long in the mind of the learner which can influence his or her behaviour. One student of a teacher who participated in ROOTs program expressed her insights about attending a learning session where her teacher applied FIRST:

"It's the first time I love waking up early to go to university. It was a pleasure! I took linguistics before, and I didn't like it at all. I dropped the course. However, with you I changed my mind." (A student of a Female Participant).

\section{Student Engagement}

FIRST framework aims to provide teachers with effective teaching strategies and methods that can increase their students' engagement (Hu and Kuh, 2002).

"The learners manifested higher degrees of active participation and happiness than in ordinary teaching and learning. The learners had great insights, as they were interested to be involved in the class from the beginning to the end." (A Male Participant).

\section{Student Motivation}

Bahgat et al. (2018) suggested that for leaners to be active they should be motivated and it is the role of educator to motivate the learner. One of program participants stated about FIRST framework:

"This learner centric approach motivated learners so much, I could see how enthusiastic my students during the learning process." (A Male Participant).

\section{Theme 6: Impact of FIRST on Organization after the Program}

\section{Impact of FIRST on Schools}

Some participant reported that their school started to populate FIRST skills and strategies among school teachers such as RAWFED School in Lebanon, RAHMA School in Tanzania. As one of the participants stated:

"The school principal had another insight which was how to let their teachers apply FIRST in their classes and how to make it a life habit for them at the school; it has brought a change to our school and among the teachers." (A Female Participant)

\section{Quantitative Data Analysis}


The survey questionnaire consisted of 14 questions as shown in Table 1 . The survey was designed based on the qualitative part (Creswell, 2014). Participants indicated their agreement on each item on a four-point Likert scale (1 - strongly disagree, and 4 - strongly agree). To examine the factor structure of the survey items, an exploratory factor analysis was carried out using Principal component analysis and Varimax rotation. The reliability of each factor has been assessed using Cronbach's alpha. The descriptive statistics that present the central tendency and variability of the two factors are shown in Table 2.

\section{Factor Analysis}

To assess the data is sufficient and suitable for factor analysis, Kaiser-Meyer-Olkin (KMO) and Bartlett's test of Sphericity were conducted. KMO value was 0.913 which is greater than 0.7 . This indicated that the survey is suitable for factor analysis and it should result in separate factors (Field, 2009). Barlett's test result indicated Chi square of 1068.926 with 91 degree of freedom and a significance value of 0.000 which indicated that factors for those variables exist (Hair et al., 2010). Two factors with Eigenvalues greater than one are extracted (Tabachnick and Fidell, 2007). The results in Table 1 indicate that items were loaded on these two factors. The first factor 'Relevance of FIRST' had eigenvalue of 6.975 and it contributed to $48.24 \%$ in the total variance. The second factor 'Transfer of Learning' had the eigenvalue of 2.589 and explained $18.491 \%$ of total variance.

\section{Reliability}

Cronbach's alpha was used to assess the internal consistency and to test the reliability of the two factors. Both factors exhibited high values of Cronbach's alpha as shown in Table 1. The first factor 'Relevance of FIRST' has a reliability of .962 and 'Transfer of Learning' has a reliability of .763. Both values are reasonably accepted as they are above 0.7 as suggested by Nunnally (1987).

\begin{tabular}{lllll}
\hline & Factor & Eigen & Variance & Factor \\
Items & Loadings & Value & Explained & reliability \\
\hline
\end{tabular}




\begin{tabular}{|c|c|c|c|c|}
\hline Factor 1: Relevance & & 6.96 & 49.82 & .96 \\
\hline $\begin{array}{l}\text { Q1:The development program was relevant to my } \\
\text { teaching/training job and met my interests }\end{array}$ & .90 & & & \\
\hline Q2:What I learned will help me to do my teaching job better & .92 & & & \\
\hline $\begin{array}{l}\text { Q3:I feel confident about applying FIRST in my daily } \\
\text { teaching practices }\end{array}$ & .71 & & & \\
\hline Q4:The program materials were well organized & .94 & & & \\
\hline $\begin{array}{l}\text { Q5:Learning activities were well developed and promoted } \\
\text { learning }\end{array}$ & .93 & & & \\
\hline $\begin{array}{l}\text { Q6:The provided learning environment promoted deep } \\
\text { learning }\end{array}$ & .88 & & & \\
\hline $\begin{array}{l}\text { Q7:The facilitators demonstrated an excellent understanding } \\
\text { of the content }\end{array}$ & .88 & & & \\
\hline $\begin{array}{l}\text { Q8:The facilitators demonstrated an excellent ability in } \\
\text { facilitating various discussions }\end{array}$ & .94 & & & \\
\hline Q9:My participation was encouraged by the facilitator & .79 & & & \\
\hline Factor 2: Transfer & & 2.59 & 18.49 & .76 \\
\hline $\begin{array}{l}\text { Q10:I believe that FIRST helps me do my current job } \\
\text { (teach/train/educate) better. }\end{array}$ & .72 & & & \\
\hline $\begin{array}{l}\text { Q11:My job (teaching) performance improves when I apply } \\
\text { what I have learned in FIRST training. }\end{array}$ & .68 & & & \\
\hline $\begin{array}{l}\text { Q12:I am able to overcome obstacles on my teaching job that } \\
\text { hinder my use of new skills and knowledge that I learned in } \\
\text { FIRST training. }\end{array}$ & .72 & & & \\
\hline $\begin{array}{l}\text { Q13:The instructional aids (activities, illustrations, etc.) used } \\
\text { in FIRST training are very similar to real things I use on } \\
\text { teaching "training" job. }\end{array}$ & .71 & & & \\
\hline $\begin{array}{l}\text { Q14:The activities and exercises that I exercised helped me } \\
\text { know how to apply my learning on the job. }\end{array}$ & .75 & & & \\
\hline
\end{tabular}

\section{Descriptive Statistics}

Table 2: Descriptive Statistics

\begin{tabular}{lllll}
\hline Factor & Mean & Median & Mode & Std. Deviation \\
\hline Relevance of FIRST & 3.65 & 3.89 & 4 & .59 \\
Transfer of Learning & 3.46 & 3.40 & 3 & .36 \\
\hline
\end{tabular}

As indicated in Table 2, the mean of Relevance of FIRST is $(M=3.65)$ where a 4-point Likert scale was used. This mean indicated the tendency of respondents toward agreeing on the relevance of FIRST framework as a professional development framework. In addition, the mean Transfer of learning is $(\mathrm{M}=3.46)$ where a 4-point Likert scale was used. This indicated the respondent's tendency towards applying FIRST in their workplace and classrooms.

\section{Discussion and Recommendations}

Interpretation of the qualitative data shows that; FIRST framework (Bahgat et al. 2018) successfully examined and validated using Quantitative, Qualitative, and Mixed Methods, as a TPD program allowed teachers to live the learning experience as learners where they felt engaged with the program and motivated to participate and apply the teaching methods that they learnt just after finishing the program. Applying FIRST changed teachers' 
mindset towards their role to become learning facilitators and to be student-centred. On the level of their schools, some teachers illustrated how their colleagues were inspired by the new methods of learning facilitation. On the student levels, some of the teachers indicated that their learners felt more engaged and expressed that they had a good learning experience; moreover, they become more motivated and engaged in the class. Quantitative data analysis showed that teachers considered FIRST as a relevant TPD program to their job. Also, data analysis showed that teachers applied FIRST framework strategies and principles in their classrooms.

Besides combining coaching and mentoring, traditional training and CoP as suggested by Kennedy (2005), the authors recommend adding two important aspects, first to encourage teachers to relate their previous experience and knowledge with the newly proposed knowledge and skills to construct their own new knowledge and learning. Second, authors argue that teachers should live the experience as learners themselves to be able to provide this experience to their students and learners. Furthermore, the researchers recommend that the learning transfer should start from within the classroom, which will guarantee the transfer and increase its momentum. Therefore, all research paper questions raised found to be significantly valid with positive impact on Teachers, Teachers Experience, Teachers Professional Development TPD, Students Experience, and School/Educational Organizations.

\section{Conclusion}

In order to prepare teachers for success in a rapidly changing environment in the education sector, TPD programs must provide teachers with research-based approaches that are relevant to their practices. The authors suggested in this study to let teachers live the experience as learners to enable them to provide their students with an enjoyable and sustainable learner experience. Teachers need a TPD that provides them with guidance of how to design and facilitate students learning. Teachers who participated in the program expressed their gratitude about FIRST as a TPD program that allows them to apply theories into practical situations. The impact that FIRST as TPD has on transforming teachers' perceptions about their role in the learning process contributes to the change in both attitude and behaviour of teachers to become learning facilitators who care about their students' experience. Moreover, TPD using FIRST pave the way for the teachers to transfer learning, creating engagement and achieving a sustainable impact for their students. As discussed in this paper, teachers who participated in the FIRST program - from what they reported- have demonstrated the three dimensions of impact of FIRST framework: First, the teachers themselves, who felt the change, lived a memorable and impactful learning experience, became motivated and engaged in the learning event and are able to transfer what they learnt into performance in the workplace. Second, students expressed their appreciation for the engaging and exciting learning experience that was taught through FIRST framework. The Third and final dimension of impact is represented in the schools and institutions that are considering adopting FIRST framework as a teaching strategy for design and learning facilitation by their teachers. Finally, FIRST framework (Bahgat et al. 2018) proven successfully to be a valid significant framework using Exploratory Sequential Mixed Methods, as a TPD program that allowed teachers to live the learning experience as learners.

\section{References}

Aiello, P., Sharma, U. (2018). Improving intentions to teach in inclusive classrooms: The impact of teacher education courses on future learning support teachers. Form@Re - Open Journal Per La Formazione In Rete, 18(1), 207-219. doi:10.13128/formare-22605

Ajzen, I., and Fishbein, M. (1980). Understanding Attitudes and Predicting Social Behavior, Prentice-Hall, Englewood Cliffs, NJ.

Ajzen, I. (1991). The theory of planned behavior: Some unresolved issues. Organizational Behavior and Human Decision Processes, 50, 179-211.

Akhavan, P., Marzieh, B., \& Mirjafari, M. (2015). Identifying the success factors of communities of practice (CoPs). VINE, 45(2), 198-213. doi:10.1108/vine-03-2014-0022. 
Angadi, G. R. (2013). Best Practices in Teacher Professional Development. International Journal of Education and Psychological Research (IJEPR),ISSN: 2279-0179 Volume 2, Issue 2, pp: 8-12.

Bahgat, M., Elsafty, A., Shaarawy, A., \& Said, T. (2018). First framework design and facilitate active deep learner experience. Journal of Education and Training Studies, 6(8), 123. doi:10.11114/jets.v6i8.3337

Benckendorff, P., Ruhanen, L., \& Scott, N. (2009). Deconstructing the student experience: A conceptual framework. Journal of Hospitality and Tourism Management, 16(1), 84-93.

Bharati, P.L., \& Chalise,S. (2017). Teacher Development: Strategies and Perception. The Saptagandaki Journal, 8, 69-78.

Biggs, J., \& Tang, C. (2011). Teaching for Quality Learning at University. SHRE and Open University Press.

Bonwell, C. C., \& Eison, J. A. (1991). Active learning: Creating excitement in the classroom. (ASHE-ERIC Higher Education Report No. 1). Washington, DC: George Washington University.

Boud, D., Cohen, R., \& Walker, D. (1993). Using experience for learning. Milton Keynes, United Kingdom: McGraw-Hill Education (UK).

Bransford, J.D., Brown, A.L., \& Cocking, R.R. (Eds.). (2000). How people learn: Brain, mind, experience, and school. Washington, DC: National Academy Press.

Castañeda, S. (2016). Methodologies for teaching English to adult students in Spanish vocational education programs. Journal of Professional, Continuing, and Online Education, 2(1).

Craft, A. (2002). Creativity and early years education: a lifewide foundation. London, England: Bloomsbury Publishing.

Creswell, J. W. (2014). Research design: Qualitative, quantitative, and mixed methods approaches. Thousand Oaks, CA: SAGE.

Curran, E., \& Murray, M. (2008). Transformative learning in teacher education: Building competencies and changing dispositions. Journal of the Scholarship of Teaching and Learning, 8(3), 103-118.

Day, C. (1994). Personal development planning: a different kind of competency. British Journal of In-Service Education, 20(3), 287-302. doi:10.1080/0305763940200302

Day, C. (1999). Developing teachers: the challenges of lifelong learning. London: Falmer Press.

Field, A. (2009) Discovering Statistics Using SPSS. (3rd ed.), Sage Publications Ltd., London.

Fraser, C., Kennedy, A., Reid, L., \& Mckinney, S. (2007). Teachers' continuing professional development: Contested concepts, understandings and models. Journal of In-Service Education,33(2), 153-169. doi:10.1080/13674580701292913

Fullan, M. (2000). The return of large-scale reform. Journal of Educational Change, vol. 1.

Ganser, T. (2000). An ambitious vision of professional development for teachers. NASSP Bulletin, 84(618), 612. doi: $10.1177 / 019263650008461802$

Georgiou, H., \& Sharma, M. D. (2014). Does using active learning in thermodynamics lectures improve students' conceptual understanding and learning experiences? European Journal of Physics, 36(1), 015020. doi:10.1088/0143-0807/36/1/015020

Glatthorn, A. (1995). Teacher development. In L.W. Anderson (Ed.). International Encyclopedia of Teaching and Teacher Education. (2nd ed.). London: Pergamon Press.

Grossman, P.L. (1994) In pursuit of a dual agenda: creating a middle level Professional Development School. In: L. DARLING-HAMMOND (Ed.) Professional Development Schools: schools for developing a profession (New York, Teachers College Press) pp. 50-73.

Gregory, A., Allen, J. P., Mikami, A. Y., Hafen, C. A., \& Pianta, R. C. (2013). Effects Of A Professional Development Program On Behavioral Engagement Of Students In Middle And High School. Psychology in the Schools, 51(2), 143-163. doi:10.1002/pits.21741

Guskey, T. R., and Huberman, M. (1995). Professional development in education: New paradigms and practices. New York: Teachers College Press.

Guskey, T. R. (2000). Evaluating professional development. Thousand Oaks, CA: Corwin Press. 
Hair, J.F., Black, W.C., Babin, B.J. and Anderson, R.E. (2010) Multivariate Data Analysis. 7th Edition, Pearson, New York.

Harvey, L., Burrows, A., \& Green, D. (1992). Total student experience: A first report of the QHE national survey of staff and students' views of the important criteria of quality. Birmingham, UK: QHE.

Hu, S.P, \& Kuh, G.D. (2002). Being (dis)engaged in educationally purposeful activities: The influences of student \& institutional characteristics. Research in Higher Education, 43(5), 555-75

Karalis, T. (2016). Cascade approach to training: Theoretical issues and practical applications in non-formal education. Journal of Education and Social Policy. 3. 104-108.

Kelchtermans, G. (2004). CPD for professional renewal: moving beyond knowledge for practice. In C. Day \& J. Sachs (Eds.), International Handbook on the Continuing Professional Development of Teachers (pp. 217-237). Maidenhead: Open University Press.

Kennedy, A. (2005). Models of continuing professional development: a framework for analysis. Journal of Inservice Education, 31(2), 235-250. doi:10.1080/13674580500200358

Koster, B., Dengerink, J., Korthagen, F., \& Lunenberg, M. (2008). Teacher educators working on their own professional development: goals, activities and outcomes of a project for the professional development of teacher educators. Teachers and Teaching, 14(5-6), 567-587.

Laird, T. N., Shoup, R., \& Kuh, G. (2005). Deep learning and college outcomes: Do fields of study differ? The Annual Meeting of the Association for Institutional Research, May 29 - June 1, 2005 San Diego, CA.

Lave, J., \& Wenger, E. (1991). Situated learning: Legitimate peripheral participation. Cambridge, England: Cambridge University Press.

Longworth, N. (2001). Learning communities for a learning century. International Handbook of Lifelong Learning, 591-617. Springer Netherlands. doi:10.1007/978-94-010-0916-4_30

Manthiou, E., Lee, S., \& Liang, T. R. (2011), "'Measuring the Experience Economy and the Visitors Behavioral Consequences: An Empirical Study on Veishea Event", 16th Graduate Students Research Conference, Houston, TX, USA.

Marchand, T. (2012). Reticence in the classroom: Examples, causes, and suggestions for improvement. Obirin Today, 12, 159-180.

Mezirow, J. (1994). Understanding transformation theory. Adult Education Quarterly, 44(4), 222-232.

Mezirow, J. (1996). Contemporary paradigms of learning. Adult Education Quarterly, 46(3), 158-172.

Mor, Y., Craft, B. \& Hernández Leo, D. (2013). The art and science of learning design: Editoral. Research in Learning Technology, 21, 22513.

Nunnally, J.C. (1987), Psychometric Theory, 2nd ed., McGraw-Hill, New York, NY.

Penuel, W. R., Fishman, B. J., Yamaguchi, R., \& Gallagher, L. P. (2007). What makes professional development effective? Strategies that foster curriculum implementation. American Educational Research Journal, 44(4), 921-958. doi:10.3102/0002831207308221

Pine, B. J., \& Gilmore, J. H. (1999). The experience economy: Work is theatre \& every business a stage. Harvard Business Press.

Pintrich, P. R., \& De Groot, E. V. (1990). Motivational and self-regulated learning components of classroom academic performance. Journal of Educational Psychology, 82(1), 33-40.

Ratey, M. (2001). A user's guide to the brain: Perception, attention, and the four theatres of the brain. 1st Vintage Books ed. New York: Vintage Books.

Rose, J. \& Reynolds, D. (2006). Teachers' continuing professional development: A new approach. In: Paper presented at 20th Annual World International Congress for School Effectiveness and Improvement.

Schunk, D. H., Pintrich, P. R., \& Meece, J., L. (2008). Motivation in education: Theory, Research, and Applications, (4th ed.). Pearson Education, Boston, MA

Subedi, B. S. (2004). Emerging trends of research on transfer of learning. International Education Journal, 5(4), 591-599.

Tabachnick, B. G., \& Fidell, L. S. (2007). Using multivariate statistics (5th ed.). Boston: Allyn and Bacon. 
Taylor, E. W. (2000). Fostering transformative learning in the adult education classroom. The Canadian Journal of the Study of Adult Education, 14, 1-28.

Taylor, E. W. (2016). Teacher transformation: a transformative learning perspective. Italian Journal of Educational Research, (15), 17-26.

Trowler, V. (2010), Student engagement literature review, The Higher Education Academy, 11(1),1-15

Wenger, E. (1998). Communities of practice: Learning, meaning, and identity. Cambridge: Cambridge University Press.

Yin, R. (2014). Case study research: Design and methods (4th ed.). Thousand Oaks, CA: Sage. 